\title{
Scanning-tunneling-microscopy studies of the S-induced reconstruction of $\mathrm{Cu}(100)$
}

\section{Colaianni, Maria Loredana; Chorkendorff, Ib}

\section{Published in:}

Physical Review B

Link to article, DOI:

10.1103/PhysRevB.50.8798

Publication date:

1994

Document Version

Publisher's PDF, also known as Version of record

Link back to DTU Orbit

Citation (APA):

Colaianni, M. L., \& Chorkendorff, I. (1994). Scanning-tunneling-microscopy studies of the S-induced reconstruction of $\mathrm{Cu}(100)$. Physical Review B, 50(12), 8798-8806. https://doi.org/10.1103/PhysRevB.50.8798

\section{General rights}

Copyright and moral rights for the publications made accessible in the public portal are retained by the authors and/or other copyright owners and it is a condition of accessing publications that users recognise and abide by the legal requirements associated with these rights.

- Users may download and print one copy of any publication from the public portal for the purpose of private study or research.

- You may not further distribute the material or use it for any profit-making activity or commercial gain

- You may freely distribute the URL identifying the publication in the public portal

If you believe that this document breaches copyright please contact us providing details, and we will remove access to the work immediately and investigate your claim 


\title{
Scanning-tunneling-microscopy studies of the S-induced reconstruction of $\mathbf{C u}(100)$
}

\author{
M. L. Colaianni* and I. Chorkendorff \\ Physics Department, Building 307, Technical University of Denmark, DK-2800 Lyngby, Denmark
}

(Received 23 March 1994)

\begin{abstract}
This study utilizes Auger-electron spectroscopy, low-energy electron diffraction, and scanning tunneling microscopy (STM) to examine sulfur coverages above $\Theta_{S}=0.25$ on the $\mathrm{Cu}(100)$ surface. These large sulfur coverages are observed to induce a restructuring of the copper surface through the removal of copper atoms from terrace sites. The layer produced at room temperature by $\mathrm{H}_{2} \mathrm{~S}$ exposures is composed of small $\mathrm{Cu}-\mathrm{S}$ aggregates which do not exhibit long-range order, but which orient in the [001] and [010] directions. Heating above $873 \mathrm{~K}$ causes tetramer sulfur unit cells to form in a poorly ordered overlayer. Annealing to $1173 \mathrm{~K}$ produces a well-ordered $(\sqrt{17} \times \sqrt{17}) R 14^{\circ}$ structure which shows four sulfur atoms per unit cell in the STM images. Since the sulfur coverage of the $(\sqrt{17} \times \sqrt{17}) R 14^{\circ}$ structure has been previously measured to contain a total of eight sulfur atoms per unit cell, a structural model is proposed that is consistent with the coverage and STM measurements.
\end{abstract}

\section{INTRODUCTION}

Over the last several years, scanning tunneling microscopy (STM) has been successfully applied to study adsorbate-induced restructuring mechanisms and to examine structurally large unit cells. The usefulness of STM for studying restructuring phenomena stems from its ability to directly image mass transport on the surface during the reconstruction, giving valuable information on the composition of the resulting surface structure. Another valuable feature of STM results from its ability to examine large (and small) individual unit cells on the surface with atomic resolution, thus permitting the determination of atomic positions within a unit cell, regardless of how many domains may be present on the surface. These abilities have allowed the STM to contribute new insights into the mechanism of adsorbate-induced reconstructions and the composition and structure of the unit cells which form. ${ }^{1}$

Adsorbate-induced relaxation and restructuring of metal surfaces have been the subject of numerous studies over the last 20 years. Typically, clean metal surfaces exhibit a smaller interplanar spacing between their top two atomic planes, relative to their bulk interplanar distances. It has been shown that by coordinating adsorbates to a surface, this interlayer contraction can be relaxed, or even reversed. ${ }^{2}$ This observation can be explained by results from effective-medium theory calculations, ${ }^{3}$ which show that the charge density from adsorbents can offset the undercoordinated state of the top surface layer, resulting in its moving back towards its bulk interplanar spacing. If the increase in charge density exceeds the bulk density, the surface atoms will attempt to expand beyond their bulk interatomic spacing, resulting in an increased repulsion between the top two planes and also within the top layer of metal atoms. Such an intraplanar stress can be relieved by the ejection of atoms from the surface plane. This type of phenomenon occurs upon sulfur adsorption on $\mathrm{Ni}(111),{ }^{4,5}$ where $20 \%$ of the surface metal atoms from terraces are observed to be ejected into island structures on the surface.

Adsorbate-induced restructuring processes have been shown by STM to occur in several oxidation ${ }^{1,6}$ and sulfidation ${ }^{7}$ processes, including the oxidation of $\mathrm{Cu}(110),{ }^{8-13} \mathrm{Cu}(100),{ }^{14-16} \mathrm{Cu}(111),{ }^{17}$ and $\mathrm{Ni}(110)$ (Refs. 18 and 19) and the sulfidation of $\mathrm{Cu}(111),{ }^{20} \mathrm{Cu}(110),{ }^{21}$ and $\mathrm{Ni}(111),{ }^{4}$ though the structure proposed by this last study is being debated. ${ }^{22}$ In the oxygen-induced processes, metal atoms are generally observed to be removed from their surface sites and placed into overlayer structures consisting of metal-oxygen chains on the surface. The sulfidation studies have generally found simple sulfur overlayer structures or a reconstructed surface layer consisting of metal and sulfur atoms.

Sulfur is known to bound on $\mathrm{Cu}(100)$ in a $p(2 \times 2)$ structure when the sulfur coverage is near $0.25 \mathrm{ML}$, and to form a diffuse low-energy electron diffraction (LEED) pattern upon continued adsorption to $0.5 \mathrm{ML}$. Though one study has reported that a $c(2 \times 2)-S$ overlayer forms under specific experimental conditions, ${ }^{23}$ a $c(2 \times 2)$ structure was not observed in any of our LEED studies and has not been reported in the literature. The $\mathrm{S} / \mathrm{Cu}(100)$ interface has been examined by Auger-electron spectroscopy (AES), ${ }^{24,25}$ LEED, ${ }^{24-30}$ radioactive tracer analysis, ${ }^{26}$ angle-resolved photoelectron spectroscopy, ${ }^{31}$ $x$-ray diffraction, ${ }^{32}$ medium energy ion scattering, ${ }^{33}$ high-resolution electron energy loss spectroscopy, ${ }^{34,35}$ angle-resolved photoemission extended fine structure, ${ }^{36-39}$ surface-extended $x$-ray absorption fine structure, ${ }^{23,40,41} \mathrm{x}$-ray photoemission studies, ${ }^{42}$ and STM [on a vicinal (100) surface]. ${ }^{43}$ Most of these studies only dealt with the $p(2 \times 2)$ structure, which forms at room temperature (RT) at a sulfur coverage of approximately 0.25 ML. Results from these studies have shown that sulfur in the $p(2 \times 2)$ structure occupies the fourfold hollow site (FFHS) and induces only a small outward substrate relaxation of less than or equal to $0.03 \AA$ (Refs. 29, 32, and 39) of the copper atoms from their equilibrium position on the clean surface.

Another stable sulfur structure is found on $\mathrm{Cu}(100)$ 
after thermal annealing of sulfur coverages of approximately 0.5 ML. This structure exhibits a $(\sqrt{17} \times \sqrt{17}) R 14^{\circ}$ structure or alternatively ||$_{-1}^{4}{ }_{1}^{4} \mid$ in matrix notation. This overlayer has been the subject of several LEED studies, ${ }^{26,27,30}$ and a radioactive tracer study $^{26}$ which determined the sulfur coverage to be 0.47 $\mathrm{ML}$, i.e., $8 \mathrm{~S}$ atoms per $17 \mathrm{Cu}$ atoms in the $(\sqrt{17} \times \sqrt{17}) R 14^{\circ}$ unit cell. Several structural models have been proposed for this large unit cell. ${ }^{26,30,44}$

In this study, we utilize STM, LEED, and AES to examine the adsorption of sulfur beyond the $0.25-\mathrm{ML}$ $p(2 \times 2)$ structure, and to observe the ordering of this layer and the formation of the $(\sqrt{17} \times \sqrt{17}) R 14^{\circ}$ unit cell upon annealing. We find that large exposures of $\mathrm{H}_{2} \mathrm{~S}$ onto $\mathrm{Cu}(100)$ at $\mathrm{RT}$ cause a restructuring of the surface which involves the displacement of copper atoms from terrace sites to form small $\mathrm{Cu}-\mathrm{S}$ aggregates in the [010] and [001] directions. Upon thermal annealing, these aggregates order into tetramer unit cells with the $(\sqrt{17} \times \sqrt{17}) R 14^{\circ}$ structure. A model of this final structure is proposed.

\section{EXPERIMENT}

These studies were performed in a stainless steel ultrahigh vacuum (UHV) chamber with a base pressure below $2 \times 10^{-10}$ mbar. It contained the following spectroscopic tools: a Perkin-Elmer Auger-electron spectrometer utilizing a single-pass cylindrical mirror analyzer, a Princeton Research Instruments model 8-120 reverse view LEED, and a copper-shielded $(2 \mathrm{~mm}$ aperture) Balzers QMG421C quadrupole mass spectrometer with a $90^{\circ}$-off axis ion detector. The principal feature of this chamber is a Danish Micro Engineering (DME, Herlev, Denmark) Rasterscope 3000 UHV-version scanning tunneling microscope which was used for all the STM images reported in this work. The microscope was mounted with a home-built sample lock to accommodate our manipulator-based detachable sample holder. This sample mounting allowed the crystal to be analyzed by the aforementioned surface-sensitive techniques and also to be resistively heated and liquid-nitrogen cooled, and to be detached and transferred to the vibrationally isolated STM. ${ }^{45}$

The STM was operated in a constant-current mode. Tips were made from $0.5-\mathrm{mm}$ tungsten wire $(99.95 \%$ purity, Goodfellow, Cambridge, UK) after an electrochemical etching procedure which utilized the drop-off method for tip preparation. ${ }^{46,47}$ Several of these tips were analyzed using a transmission electron microscope (TEM). Our simple tip production setup yielded tips which terminated with a terrace less than $200 \AA$ approximately $75 \%$ of the time.

The $\mathrm{Cu}(100)$ crystals used in this work were spark cut from a single-crystal boule and then mechanically polished to mirrorlike surfaces. The crystals were then electropolished in a $\sim 60 \%$ phosphoric acid solution at $2 \mathrm{v}$ for a minimum of $1 \mathrm{~min}$. The final quality of the electropolished surfaces varied on a macroscopic level (i.e., some were mirrorlike, most were duller), but always revealed well-ordered surfaces after several cycles of sputtering and annealing to $800 \mathrm{~K}$.

In this study, sulfur was adsorbed onto the surface in three different ways. The direct exposure of $\mathrm{Cu}(100)$ at room temperature to $\mathrm{H}_{2} \mathrm{~S}$ (Linde, $98 \%$ purity, prior to two freeze-pump-thaw cycles) produces a surface with only adsorbed sulfur. This has been shown previously by a detailed study of the reaction of $\mathrm{H}_{2} \mathrm{~S}$ with $\mathrm{Cu}(100)$. In these studies $\mathrm{H}_{2} \mathrm{~S}$ was observed to decompose into $\mathrm{H}(\mathrm{a})$ and $\mathrm{HS}(\mathrm{a})$ on the surface at $100 \mathrm{~K}$, and upon warming to $130 \mathrm{~K}$ the $\mathrm{HS}(\mathrm{a})$ further decomposed into $\mathrm{H}(\mathrm{a})+\mathrm{S}(\mathrm{a}){ }^{35}$ Since hydrogen desorbs as $\mathrm{H}_{2}(\mathrm{~g})$ from the $\mathrm{Cu}(100)$ surface by $300 \mathrm{~K},{ }^{35,48,49}$ only the adsorbed sulfur remains. This method though required very large doses $\left(>10^{4} \mathrm{~L}\right)$ to achieve a coverage near $0.5 \mathrm{ML}$. A second method of adsorbing sulfur involved exposing the surface to $\mathrm{H}_{2} \mathrm{~S}$ while in line of sight of a glowing filament. This method allowed $\sim 0.5 \mathrm{ML}$ of sulfur to be deposited from only $\sim 50$ $\mathrm{L} \mathrm{H}_{2} \mathrm{~S}$ exposure. Lastly, a $\mathrm{Cu}(100)$ crystal cut from a boule contains bulk sulfur impurity. Temperatures above $873 \mathrm{~K}$ cause sulfur to segregate to the surface and result in a surface which displays a low intensity $(\sqrt{17} \times \sqrt{17}) R 14^{\circ} \mathrm{LEED}$ pattern. Annealing to $1273 \mathrm{~K}$ produces a sharp and intense $(\sqrt{17} \times \sqrt{17}) R 14^{\circ}$ pattern. It was found that this layer could be sputtered off and then regenerated numerous times $(\sim 50)$ before the bulk sulfur concentration was depleted. This effect shows that despite having a large sulfur reserve in the bulk, and heating to sufficient temperatures to allow sulfur segregation, a surface coverage above $\sim 0.5 \mathrm{ML}$ is not thermodynamically favorable.

\section{RESULTS}

\section{A. Auger-electron spectroscopy}

An AES study of sulfur uptake by $\mathrm{H}_{2} \mathrm{~S}$ exposure to $\mathrm{Cu}(100)$ at $300 \mathrm{~K}$ is shown in Fig. 1. Sulfur adsorption occurs in two stages, labeled in Fig. 1 as Stages I and II for sulfur coverages up to and beyond $\Theta_{S} \sim 0.25 \mathrm{ML}$, respectively. The onset of adsorption in Stage $I$ is initiated

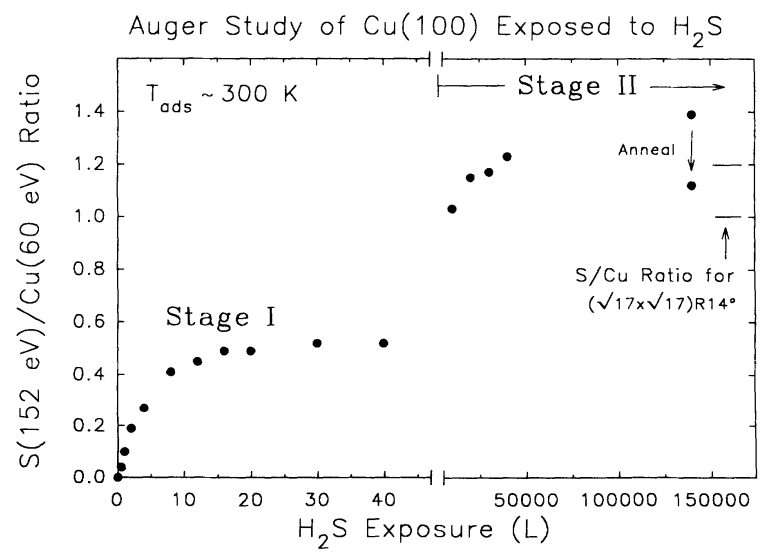

FIG. 1. Sulfur uptake on $\mathrm{Cu}(100)$ after $\mathrm{H}_{2} \mathrm{~S}$ exposures as monitored by the $S(152 \mathrm{eV}) / \mathrm{Cu}(60 \mathrm{eV})$ peak-to-peak height ratio. The anneal corresponds to $673 \mathrm{~K}$ for $3 \mathrm{~min}$. 
by a rapid uptake of sulfur between $0-8 \mathrm{~L} \mathrm{H}_{2} \mathrm{~S}$, followed by a slower sulfur uptake above $8 \mathrm{~L}$ and an apparent saturation of the surface to further sulfur adsorption near 40 L. However, as revealed in Fig. 1, increased quantities of sulfur can be adsorbed onto $\mathrm{Cu}(100)$, but much larger $\mathrm{H}_{2} \mathrm{~S}$ exposures are necessary (Stage II in Fig. 1). An additional exposure of $10^{4} \mathrm{~L} \mathrm{H}_{2} \mathrm{~S}$ is required to double the $\mathrm{S}(152 \mathrm{eV}) / \mathrm{Cu}(60 \mathrm{eV})$ AES ratio which is observed after only 40-L exposure. This drastically reduced rate for sulfur adsorption suggests, and the STM results will confirm, that a different sulfur adsorption process occurs for coverages above $0.25 \mathrm{ML}$.

Figure 1 also shows the effects of annealing high coverages of sulfur on $\mathrm{Cu}(100)$. When sulfur coverages greater than those that form the $(\sqrt{17} \times \sqrt{17}) R 14^{\circ}$ structure are adsorbed, annealing above $873 \mathrm{~K}$ causes the "excess" sulfur to diffuse into the bulk and for the $(\sqrt{17} \times \sqrt{17}) R 14^{\circ}$ structure to form. This was confirmed by temperature-programmed desorption studies which revealed that $S$ (mass 32 ) did not absorb upon heating to $873 \mathrm{~K}$. After such high-temperature excursions, the $\mathrm{S}(152 \mathrm{eV}) / \mathrm{Cu}(60 \mathrm{eV}) \mathrm{AES}$ ratio always returns to a value between 1.0 and 1.2. This confirms that sulfur coverages above $\sim 0.5 \mathrm{ML}$ are not thermodynamically stable on the $\mathrm{Cu}(100)$ surface.

\section{B. Low-energy electron diffraction}

Figure 2 shows LEED photos of the various ordered surfaces formed by sulfur bonding to $\mathrm{Cu}(100)$. A $p(2 \times 2)$-S LEED pattern is shown in Fig. 2(a) with sharp half-order spots and only a minimal amount of streaks between these spots. This signifies well-ordered $p(2 \times 2)$ domains on the surface. Some degree of streaking could always be resolved in our $p(2 \times 2)$ patterns, despite our many attempts to make the layer. STM analysis ${ }^{45,50}$ shows that the surface possesses a fairly high degree of local $c(4 \times 2)$ domain boundaries between regions of wellordered $p(2 \times 2)-\mathrm{S}$, in agreement with the LEED results of Zeng and Mitchell. ${ }^{28}$

The LEED pattern shown in Fig. 2(b) results from a $\mathrm{Cu}(100)$ surface exposed to $10^{4} \mathrm{~L} \mathrm{H}_{2} \mathrm{~S}$ and annealed to $573 \mathrm{~K}$. This type of LEED pattern is only observed when the $\mathrm{S}(152 \mathrm{eV}) / \mathrm{Cu}(60 \mathrm{eV}) \mathrm{AES}$ ratio is similar to the ratio obtained on the well-ordered $(\sqrt{17} \times \sqrt{27}) R 14^{\circ}$ structure (see Fig. 1), i.e., when the sulfur coverage is near $0.5 \mathrm{ML}$. Though similar patterns have been reported previous$1 y,{ }^{25-27}$ they have only been identified as diffuse patterns. No attempt has been made to determine the corresponding surface structure. It will be shown by STM that this structure is related to the $(\sqrt{17} \times \sqrt{17}) R 14^{\circ}$ structure, being composed of mostly $(\sqrt{17} \times \sqrt{17}) R 14^{\circ}$ unit cells and another structurally similar but larger unit cell with the matrix notation $\left|\begin{array}{ll}5 & 2 \\ 0 & 5\end{array}\right|$, and also possessing a large degree of disorder. The $\left|\begin{array}{ll}5 & 2 \\ 0 & 5\end{array}\right|$ structure has been found to be formed preferentially upon annealing a $\mathrm{H}_{2} \mathrm{~S}$ exposed preoxidized $\mathrm{Cu}(100)$ surface, and will be discussed in a separate publication. ${ }^{51}$

When the sulfided layer which produces a complex LEED pattern is annealed above $873 \mathrm{~K}$ a $(\sqrt{17} \times \sqrt{17}) R 14^{\circ}$ pattern forms which is stable until at least $1273 \mathrm{~K}$. A photo of the $(\sqrt{17} \times \sqrt{17}) R 14^{\circ}$-S LEED pattern is provided in Fig. 2(c).

The exact temperature at which the $(\sqrt{17} \times \sqrt{17}) R 14^{\circ}$ structure formed is dependent on the initial sulfur surface coverage. Higher coverages could be achieved by excep-
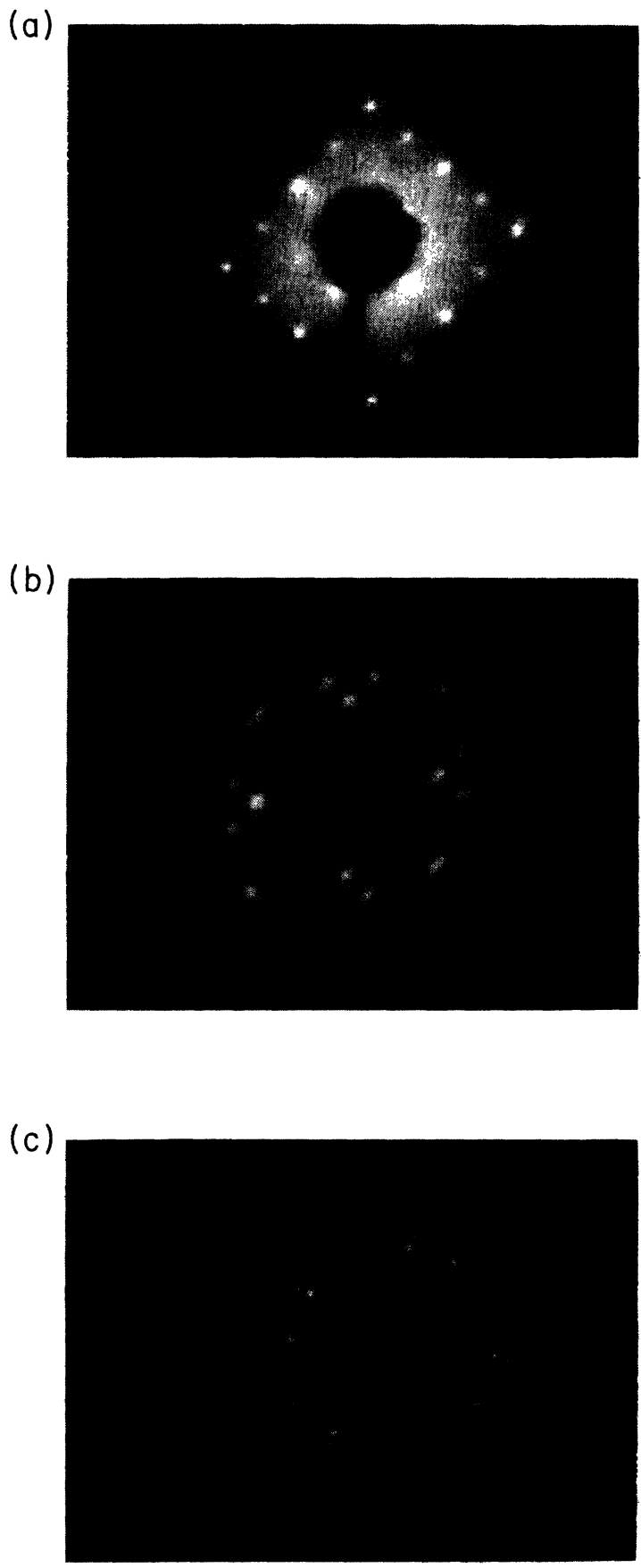

FIG. 2. LEED photos of the various sulfur structures formed on $\mathrm{Cu}(100)$ : (a) $p(2 \times 2)$ formed by $10 \mathrm{~L}$ of $\mathrm{H}_{2} \mathrm{~S}$ followed by an anneal to $573 \mathrm{~K}, E_{p}=210.9 \mathrm{eV}$; (b) a complex pattern formed by $45 \mathrm{~L}$ of $\mathrm{H}_{2} \mathrm{~S}$ with a heated filament doser followed by an anneal to $573 \mathrm{~K}, \Theta_{S} \sim 0.5 \mathrm{ML}, E_{p}=78.9 \mathrm{eV}$; (c) the $(\sqrt{17} \times \sqrt{17}) R 14^{\circ}$ pattern formed by bulk segregation of sulfur upon annealing to $1173 \mathrm{~K}, E_{p}=67.7 \mathrm{eV}$. 
tionally large $\mathrm{H}_{2} \mathrm{~S}$ doses, or by filament-assisted dosing, or by "preroughening" the surface, which can be accomplished by sputtering or preoxidizing the surface. The $(2 \sqrt{2} \times \sqrt{2}) R 45^{\circ}$-O layer which forms upon oxidation of $\mathrm{Cu}(100)$ is known to result from added $\mathrm{Cu}-\mathrm{O}$ rows along the surface [001] and [010] directions, ${ }^{14-16}$ resulting in a more open copper structure for binding sulfur. ${ }^{51}$ The lowest temperature observed to form a $(\sqrt{17} \times \sqrt{17}) R 14^{\circ}$ layer was $623 \mathrm{~K}$.

It should be added that sulfur coverages of $\sim 0.50 \mathrm{ML}$ deposited onto $\mathrm{Cu}(100)$ at $300 \mathrm{~K}$ do not produce structurally-ordered LEED patterns or STM images revealing any long-range order. Only after annealing to $573 \mathrm{~K}$ [Fig. 2(b)] does ordering take place. As will be confirmed by the STM results, higher coverages of sulfur adsorb onto a $\mathrm{Cu}(100)$ surface at room temperature via a substrate restructuring mechanism which does not produce any long-range order, although short-range atomic ordering is found.

\section{STM results}

\section{S-induced restructuring of $\mathrm{Cu}(100)$ terraces}

The restructuring of clean $\mathrm{Cu}(100)$ terraces by large $\mathrm{H}_{2} \mathrm{~S}$ exposures is shown in Figs. 3(a1-a4). Three clear flat terraces (and a small fraction of a fourth) are pictured prior to $\mathrm{H}_{2} \mathrm{~S}$ exposure in Fig. 3(a1). It is important to note the position of the step edges and the overall smoothness of the terraces prior to $\mathrm{H}_{2} \mathrm{~S}$ exposure. Upon scanning the same surface area during $\mathrm{H}_{2} \mathrm{~S}$ exposures of $6 \times 10^{3}$ L [Fig. 3(a2)], $1.5 \times 10^{4}$ L [Fig. 3(a3)], and $2.1 \times 10^{4}$ L [Fig. 3(a4)], we see clearly that the step edges firmly retain their positions, while the terraces undergo a roughening process as revealed by their resultant color distribution. To illuminate this roughening effect, height distributions of the clean and $2.1 \times 10^{4} \mathrm{~L} \mathrm{H}_{2} \mathrm{~S}$-exposed terraces re shown in Figs. 3(b1) and 3(b2), respectively. A comparison of the total area under each peak in the height distributions before and after $\mathrm{H}_{2} \mathrm{~S}$ exposure reveals that the areas of the terraces are unaffected (with $\pm 1.0 \%$ ), as expected for a process which does not involve repositioning of the steps. However, the peak's full widths at half maximum (FWHM) are broadened by an average factor of 2.8 after $2.1 \times 10^{4} \mathrm{~L} \mathrm{H}_{2} \mathrm{~S}$ exposure. Since a "simple" sulfur overlayer should not produce such a large increase in the FWHM of the terrace height distributions, these results suggest a roughening of the terraces due to a terrace restructuring mechanism.

This conclusion is supported by using STM to analyze the terraces on an atomic scale after this high coverage restructuring process. Figures $4(a)-4(d)$ show progressively smaller areas of the copper surface after an $\mathrm{H}_{2} \mathrm{~S}$ exposure of $2.0 \times 10^{4} \mathrm{~L}$ at $\mathrm{RT}$. We see immediately from the wide area scan [Fig. 4(a)] that the surface is composed of randomly shaped islands and crevasses with depths between 1.3-2.5 $\AA$. The depressed regions are not as clearly imaged as the top layer islands, but appear to be composed of atomic features in groups of four and six, similar to those observed on the surface island structure. By scanning the islands with atomic resolution we see that they are composed of small two-, four-, and sixmembered groups and very short chainlike structures of atoms oriented perpendicular to the close-packed directions on $\mathrm{Cu}(100)$. Also, the chains appear to exist predominantly as single rows, and not longer than six atoms in length [Figs. 4(b)-4(d)]. Though these features order in the [001] and [010] crystallographic directions, long-range order is not found in the scans. Overall, these STM results concur with the diffuse LEED pattern observed for this layer after formation at RT (Sec. III B).

Shown in Figs. 5(a) and 5(b) are STM images of a S/Cu (a)
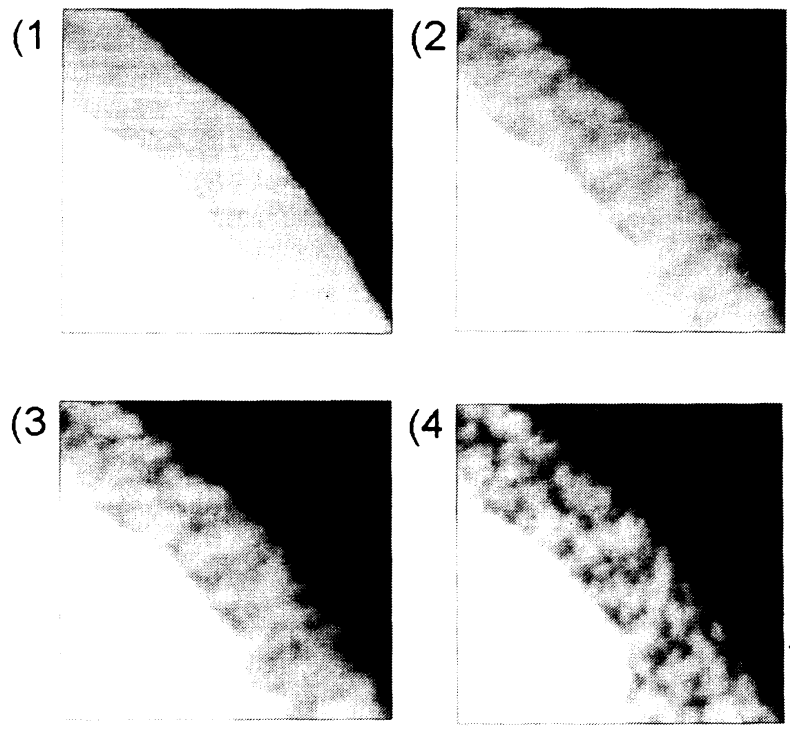

(b)
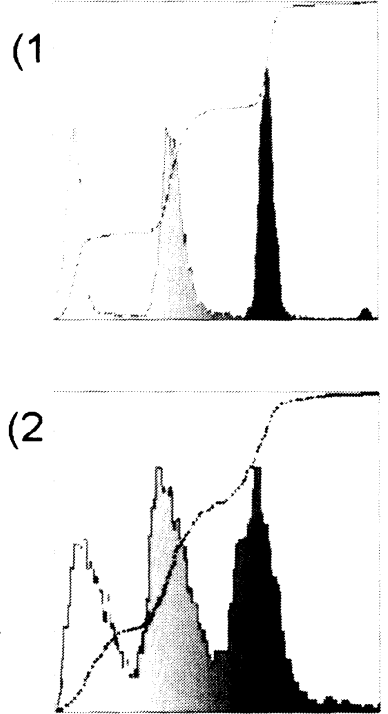

FIG. 3. (a) STM images of a $885 \times 885 \AA^{2}$ area on the $\mathrm{Cu}(100)$ surface showing the effects of $\mathrm{H}_{2} \mathrm{~S}$ exposure on the $\mathrm{Cu}(100)$ surface at room temperature: (1) clean flat terraces; (2) $6 \times 10^{3} \mathrm{~L}$ $\mathrm{H}_{2} \mathrm{~S}$; (3) $1.5 \times 10^{4} \quad \mathrm{~L} \quad \mathrm{H}_{2} \mathrm{~S}$; (4) $2.1 \times 10^{4} \mathrm{~L}$. Scans were recorded during $\mathrm{H}_{2} \mathrm{~S}$ exposure. Note that the position of the step edges remains unaffected as the terraces roughen. All images recorded at a sample bias of $+0.084 \mathrm{~V}$ and at a tunneling current of $1.17 \mathrm{nA}$. (b) Height distributions of (1) the clean $\mathrm{Cu}(100)$ surface measured from (a1), which has a total $z$ height of $6.4 \AA$; and (2) the roughened layer shown in (a4), which has a total $z$ height of $9.4 \AA$. 

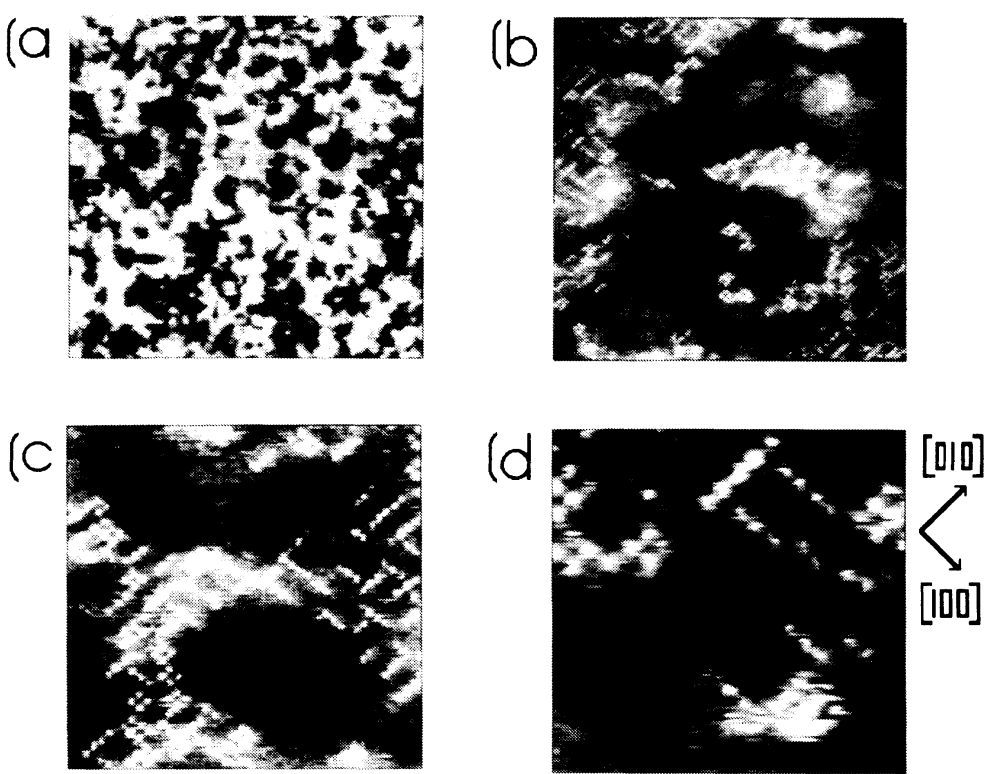

FIG. 4. STM images of the $\mathrm{Cu}(100)$ surface after being exposed to $2 \times 10^{4} \mathrm{~L} \mathrm{H}_{2} \mathrm{~S}$ at room temperature: (a) $771 \times 771 \AA^{2}$; (b) $278 \times 278$ $\AA^{2}$; (c) $139 \times 139 \AA^{2}$; (d) $69 \times 69 \AA$. The sulfur atoms are observed as protrusions in the [001] and [010] directions. Sample bias $\left(V_{b}\right)$ and tunneling currents $\left(I_{t}\right)$ were (a) $V_{b}=+0.540 \mathrm{~V}$ and $I_{t}=0.69 \mathrm{nA}$; (b), (c), and (d) $V_{b}=+0.010$ $\mathrm{V}$ and $I_{t}=1.38 \mathrm{nA}$. interface possessing an Auger $\mathrm{S}(152 \mathrm{eV}) / \mathrm{Cu}(60 \mathrm{eV})$ ratio of 1.1 after annealing to $673 \mathrm{~K}$. The onset of long-range ordering on the surface is clearly observed. For example, it is obvious that the "etched" appearance of the $\mathrm{H}_{2} \mathrm{~S}$ exposed surface at RT [Figs. 3(a4) and 4(a)] is replaced by relatively smooth terraces after the anneal [Fig. 5(a)]. Also, it is apparent that the most stable configuration of the surface is in units which are imaged as groups of four atoms, though some units of six are also observed. Lastly, these units are shown to begin to order with respect to neighboring units after an anneal to $673 \mathrm{~K}$ [Fig. 5(b)]. Further heating to $1173 \mathrm{~K}$ reveals a very well-ordered $(\sqrt{17} \times \sqrt{17}) R 14^{\circ}$ layer, in both LEED [Fig. 2(c)] and STM analysis [Fig. 5(c)].

\section{The $\sqrt{17} \times \sqrt{17} R 14^{\circ}-S$ unit cell}

Figure 5(d) shows a close-up scan of the $(\sqrt{17} \times \sqrt{17}) R 14^{\circ}$ layer with an outline of the unit cell displayed by a solid white line. The unit cell of the $(\sqrt{17} \times \sqrt{17}) R 14^{\circ}$ layer is always observed to contain four atoms in a square configuration. No additional atomic features in the unit cell were resolved, despite attempts to vary the sample bias $(-1.0$ to $+1.2 \mathrm{~V})$ and tunneling current $(0.2-2.0 \mathrm{nA})$. Using a calibrated scanning tunneling microscope, the dimensions of this unit cell were measured to be $10.5 \pm 0.15 \AA$, as expected for a $\sqrt{17} a_{0}$ unit cell length on $\mathrm{Cu}(100)$, and the resolved features within the unit cell were measured to be
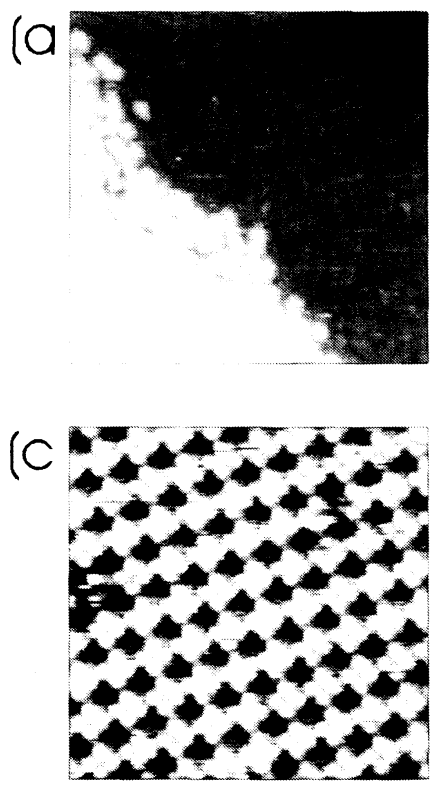
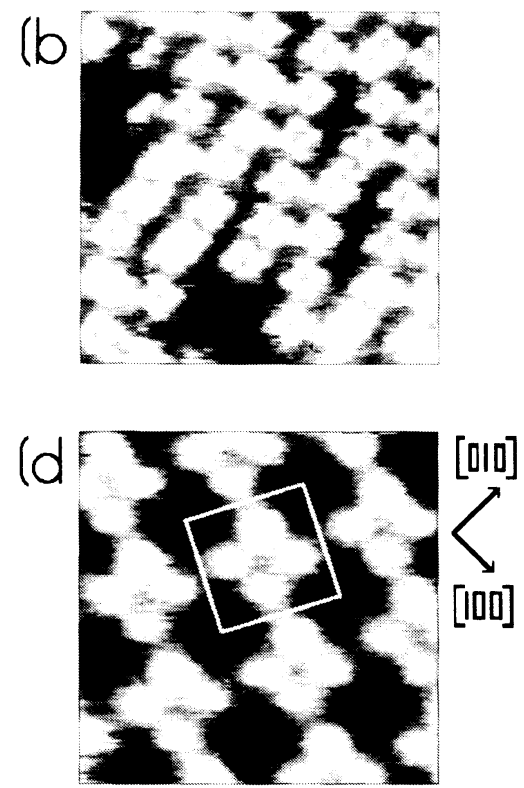

FIG. 5. STM images showing the ordering of a sulfur overlayer, $\sim 0.5 \mathrm{ML}$, on a $\mathrm{Cu}(100)$ surface. (a) $(272 \times 272 \AA)$ and (b) $(87 \times 87 \AA)$ show the surface after an anneal to $673 \mathrm{~K}$. (c) $(93 \times 93 \AA)$ and (d) $(29 \times 29 \AA)$ show the surface after an anneal to $1173 \mathrm{~K}$. Sample bias $\left(V_{b}\right)$ and tunneling currents $\left(I_{t}\right)$ were (a) $V_{b}=+0.014 \quad \mathrm{~V}$ and $I_{t}=0.29 \mathrm{nA} ; \quad$ (b) $V_{b}=+0.018 \mathrm{~V}$ and $I_{t}=0.34 \mathrm{nA}$; (c) and (d) $V_{b}=+0.005 \mathrm{~V}$ and $I_{t}=2.35 \mathrm{nA}$. 
$4.0 \pm 0.15 \AA$ from their nearest neighbors. Although this spacing is larger than the $\sqrt{2} a_{0}$ distance $(3.6 \AA)$ between the FFHS in the [001] and [010] directions on $\mathrm{Cu}(100)$, it is these directions that the neighboring sulfur atoms within each unit cell align themselves. This will be explained in the next section.

\section{DISCUSSION}

A clearer understanding of the sulfur-induced structures observed in this study is achieved if we first identify the protrusions observed in the STM images. This will allow us to propose a structure for the $(\sqrt{17} \times \sqrt{17}) R 14^{\circ}$ overlayer, and to briefly discuss the structures of the disordered layers. Lastly, we will comment on the restructuring mechanism responsible for the observed trends.

In order to properly interpret the STM images, we will need to establish the chemical identity of the resolved protrusions. Calculations performed by Lang ${ }^{52,53}$ reveal that for a sample bias between -2.0 and $+1.3 \mathrm{~V}$, sulfur adsorbed on a metal surface will appear as a protrusion, since sulfur adds to the Fermi-level state density within this energy range. In addition, STM has been used to examine sulfur adsorption on a variety of metal surfaces, such as $\mathrm{Cu}(111),{ }^{20} \mathrm{Cu}(110),{ }^{21} \mathrm{Cu}(11,1,1),{ }^{43} \mathrm{Ni}(111),{ }^{4}$ $\mathrm{Ni}(110),{ }^{18,19} \operatorname{Re}(0001),{ }^{54,55} \operatorname{Pd}(111),{ }^{56} \operatorname{Pd}(100),{ }^{57}$ and Mo(100). ${ }^{58}$ In each of these cases, sulfur was reported to appear as protrusions in the STM images. Therefore, based on the calculations and the results from these studies, we can assign our observed protrusions as arising from $S$ atoms on the substrate.

\section{A. Structure of the $(\sqrt{17} \times \sqrt{17}) R 14^{\circ}$-S overlayer}

Heating $\sim 0.5 \mathrm{ML}$ sulfur on a $\mathrm{Cu}(100)$ surface to 1173 $\mathrm{K}$ forms a well-ordered $(\sqrt{17} \times \sqrt{17}) R 14^{\circ}$ layer. This structure exhibits a sharp LEED pattern as shown in Fig. 2(c), and is shown by STM to consist of extremely wellordered terraces composed entirely of unit cells which are imaged as groups of four sulfur atoms, shown in Figs. 5(c) and 5(d). These STM images of the surface layer can be used to immediately rule out earlier proposed models for the $(\sqrt{17} \times \sqrt{17}) R 14^{\circ}$ structure. $^{26,27,30}$ The model of Domange and Oudar, ${ }^{26}$ shown in Fig. 6(a), should show eight sulfur-related features per unit cell in the STM images, with an interatomic spacing of $3.7 \AA$. Though this model does account for the measured sulfur coverage of $0.47,{ }^{26}$ it is clear from the STM image that only four of the eight sulfur atoms are imaged per unit cell and that their interatomic separation is $4.0 \pm 0.15 \AA$.

Another model is needed which better describes our STM results. We will begin by proposing that the four sulfur atoms observed in our STM analysis are found on top of the copper surface in pseudo-FFHS (to be discussed), since sulfur prefers to bond in high coordination sites, and since the imaged sulfur atoms are in the proper orientation for FFH sites. These sulfur atoms will be referred to as surface sulfur; they are shown schematically in Fig. 6(b) as black circles.

Since each $(\sqrt{17} \times \sqrt{17}) R 14^{\circ}$ unit cell contains eight sulfur atoms, we need to incorporate four additional sulfur atoms into our model which are not observed by the STM. Bonding site assignments for these four resolved sulfur atoms can only be speculative. We propose that these four unresolved sulfur atoms are bound within the areas which are measured as $\sim 0.5-0.7-\AA$ depressions in our STM images, and further, that these sulfur atoms replace copper atoms in the top copper plane [hereafter referred to as in-plane sulfur, and shown in Fig. 6(b) as crossed-hatched circles]. Such sites would allow these sulfur atoms to achieve maximum separation from the surface-sulfur atoms, and would account for their being screened from the STM tip. The $\sim 1.8-\AA$
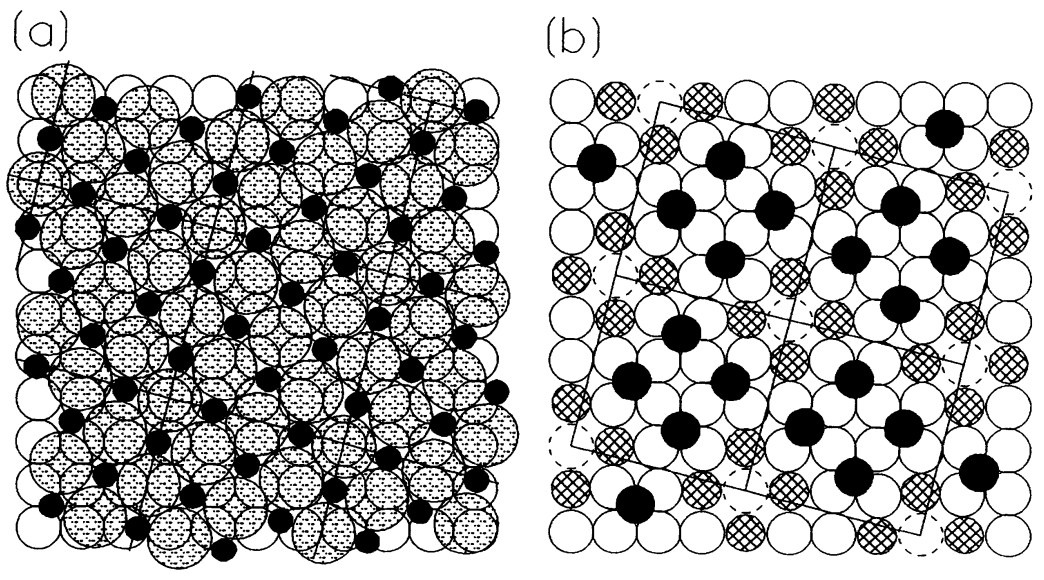

FIG. 6. (a) Model of $(\sqrt{17} \times \sqrt{17}) R 14^{\circ}$ proposed by Domange and Oudar (Ref. 26) showing a S-Cu mixed overlayer on a Cu(100) substrate. Small black circles are copper atoms and larger shaded circles represent sulfur. (b) Our proposed model based on STM analysis of the unit cell. Two types of sulfur atoms are proposed. Black circles are surface-sulfur atoms which are situated on top of pseudo-FFHS on the copper surface, and cross-hatched circles are in-plane sulfur atoms which have taken the place of terrace copper atoms within the top copper layer. The dashed circle represents a copper atom which may be absent. Spacing between the surfacesulfur atoms is measured to be $4.0 \pm 0.15 \AA$. See text for details of this model. 
depth of the in-plane sulfur below the surface-sulfur atoms may explain the shielding of these in-plane sulfur atoms from detection by the STM tip.

Our proposed replacement of surface copper atoms by in-plane sulfur atoms is compatible with the measured interatomic separation found for the surface-sulfur atoms in their assigned pseudo-FFHS. The S-Cu bond distance in $\mathrm{Cu}-\mathrm{S}$ compounds, $2.16-2.33 \AA_{,}^{59}$ and in the crystal covellite, CuS ( $d_{\mathrm{Cu}-\mathrm{S}}=2.19-2.33 \AA$ ) (Ref. 60) is shorter than the bulk $\mathrm{Cu}-\mathrm{Cu}$ bond distance $(2.55 \AA)$. This allows a lateral expansion within the top copper plane, thus forming pseudo-FFHS and permitting an increased distance between the four surface-sulfur atoms from the ideal $\sqrt{2 a_{0}}$ distance, $3.6 \AA$. This increased separation should also reduce interatomic repulsion. The final interatomic spacing between the surface-sulfur atoms is measured to be $4.0 \pm 0.15 \AA, 0.4 \AA$ further apart than the $\sqrt{2} a_{0}$ FFHS spacing on $\mathrm{Cu}(100)$, but still in approximately the same orientations as the $\sqrt{2} a_{0}$ directions, i.e., [001] and [010].

Basically, our model consists of eight sulfur atoms per unit cell - four sulfur atoms are bound on the surface in quasi-FFHS, and four in-plane sulfur atoms are believed to replace four (or five) surface copper atoms [Fig. 6(b)]. These in-plane sulfur atoms coordinate to neighboring copper atoms in the top copper plane, though these sulfur atoms may not be coplaner with this copper layer.

\section{B. Development of the $(\sqrt{17} \times \sqrt{17}) R 14^{\circ}$-S overlayer:} Onset of ordering

The layer which forms prior to complete ordering into the $(\sqrt{17} \times \sqrt{17}) R 14^{\circ}$ structure produces a diffuse LEED pattern [Fig. 2(b)] and yields STM images [Figs. 5(a) and 5(b)] which bear a strong resemblance to the ordered $(\sqrt{17} \times \sqrt{17}) R 14^{\circ}$ overlayer [Figs. 5(c) and 5(d)]. Though a large amount of disorder is observed, it is clear that the diffuse structure is composed of predominantly four-membered sulfur groups and to a lesser extent, some six-membered groups. Due to the similarity between these groups and the unit cell of the $(\sqrt{17} \times \sqrt{17}) R 14^{\circ}$ overlayer, it seems reasonable to propose that these groups possess a local structure resembling the final stable unit cell, i.e., a S-Cu aggregate with copper atoms making up the base, and sulfur atoms bound on top in high coordination sites.

\section{High-coverage sulfur adsorption on $\mathrm{Cu}(\mathbf{1 0 0 )}$ at $\mathrm{RT}$ : Surface restructuring}

Sulfur coverages up to $\sim 0.5 \mathrm{ML}$ cause a sulfurinduced restructuring of $\mathrm{Cu}(100)$ terraces [Figs. $3(\mathrm{a})-3(\mathrm{~d})$ ], not simply overlayer adsorption as occurs below $\Theta_{S}=0.25$. This restructuring mechanism produces a surface which is composed of randomly distributed islands and crevasses, as shown in [Figs. 4(a)-4(c)]. Measuring the corrugation over these regions reveals that the depth between the islands is between 1.3-2.5 $\AA$, far greater than the calculated voltage-dependent heights for an adsorbed sulfur atom in a STM image. ${ }^{53}$ Since the steps do not grow or diminish during $\mathrm{H}_{2} \mathrm{~S}$ exposure, such a large corrugation can only be explained by a process where copper atoms are removed from terrace sites and delivered to the island overlayer.

The randomly shaped islands are shown to be comprised of islands of small groups of sulfur features and very short chainlike structures oriented in the [001] and [010] directions [Figs. 4(b)-4(d)]. While this aggregation of the $\mathrm{Cu}-\mathrm{S}$ appears even at room temperature, the random shape of the islands suggest that diffusion of the $\mathrm{Cu}-\mathrm{S}$ species is limited at lower temperatures. Only upon annealing to $\geq 623 \mathrm{~K}$ is a well-ordered $(\sqrt{17} \times \sqrt{17}) R 14^{\circ}$ layer obtained.

\section{Restructuring mechanisms}

We believe that the high-coverage sulfur-induced restructuring of $\mathrm{Cu}(100)$ can be understood by employing concepts from effective-medium theory calculations, as briefly discussed in the Introduction. The basic physical picture from these calculations is that the structural discontinuity at the surface results in surface atoms which are bound in a lower electron density compared to that in their stable bulk geometry. This causes the surface atoms to decrease their interplaner distance to the second atomic layer so as to increase their surrounding charge density, i.e., their effective medium. However, when surface sites become populated with adsorbates, electron density is returned to the first layer of atoms. Their distance to the second layer can return towards the bulk distance, or depending on the surrounding charge density, even expand beyond it. ${ }^{3}$ Large expansive forces can lead to compressive surface stress between the underlayer and the overlayer, and laterally within the overlayer itself, resulting in a repulsive force between surface atoms. If the charge coordination exceeds a critical amount, it becomes possible for the surface atoms to be ejected from their surface sites. This mechanism has previously been proposed to cause the observed $20 \%$ reduction in the atomic density of the $\mathrm{Ni}(111)$ surface upon sulfur adsorption. ${ }^{4}$ Indeed, a recent study by Sanders and co-workers ${ }^{61}$ measured the sulfur-induced surface stress on $\mathrm{Ni}(100)$ as a function of sulfur coverage. They found an unusually high, nonlinear compressive (negative) surface stress, but only for sulfur coverages above $0.30 \mathrm{ML}$. We believe that this surface stress can be understood in the same manner as described above. We therefore propose that high coverages of sulfur induce large amounts of compressive surface stress which leads to the ejection of copper atoms from the surface and to the restructuring of the $\mathrm{Cu}(100)$ surface to relieve this stress.

\section{SUMMARY}

We have studied the sulfidation of the $\mathrm{Cu}(100)$ surface beyond the $\theta_{S}=0.25-\mathrm{ML} p(2 \times 2)$ structure and present the following results.

(1) Large $\mathrm{H}_{2} \mathrm{~S}$ exposures $\left(\sim 10^{4} \mathrm{~L}\right)$ are required to adsorb approximately $0.5 \mathrm{ML}$ sulfur on the $\mathrm{Cu}(100)$ surface. 
(2) If sulfur coverages above $\sim 0.5 \mathrm{ML}$ are adsorbed, annealing to $873 \mathrm{~K}$ causes the diffusion of the "excess" sulfur into the bulk copper, leaving $\sim 0.5 \mathrm{ML}$ of adsorbed sulfur and a $(\sqrt{17} \times \sqrt{17}) R 14^{\circ}$ surface structure.

(3) Large $\mathrm{H}_{2} \mathrm{~S}$ exposures cause a surface reconstruction on $\mathrm{Cu}(100)$ which involves the ejection of copper atoms from terrace sites. This reconstructed surface shows small sulfur aggregates oriented in the [001] and [010] directions and produces a diffuse LEED pattern.

(4) Annealing $\sim 0.5 \mathrm{ML}$ of sulfur on $\mathrm{Cu}(100)$ to $573 \mathrm{~K}$ produces a complex LEED pattern which is shown by STM to be composed mainly of disordered groups containing four or six sulfur atoms.

(5) Further annealing above $873 \mathrm{~K}$ produces a $(\sqrt{17} \times \sqrt{17}) R 14^{\circ}$ structure which becomes very well ordered after heating to $1173 \mathrm{~K}$.

In addition, a model is proposed for the $(\sqrt{17} \times \sqrt{17}) R 14^{\circ}$ unit cell and the surface restructuring mechanism is discussed.

\section{ACKNOWLEDGMENTS}

We would like to thank F. Besenbacher, I. Stensgaard, and E. Laegsgaard for helpful discussions and for help in fine tuning our STM apparatus. We also thank A. Henschel and R R. Thölén for use of the TEM to analyze our tips. This work was supported by the Danish Research Council through the "Center for Surface Reactivity."
*Present address: Exxon Research and Engineering Company, Corporate Research, Route 22, Annandale, NJ 08801.

${ }^{1} \mathrm{~F}$. Besenbacher and I. Stensgaard, in The Chemical Physics of Solid Surfaces and Heterogeneous Catalysis, edited by D. A. King and D. P. Woodruff (Elsevier, New York, 1993), Chap. 15.

${ }^{2}$ M. A. Van Hove and G. A. Somorjai, Surf. Sci. 299/300, 487 (1994).

3J. K. Nørskov, Rep. Prog. Phys. 53, 1253 (1990).

${ }^{4}$ L. Ruan, I. Stensgaard, F. Besenbacher, and E. Laegsgaard, Phys. Rev. Lett. 71, 2963 (1993).

${ }^{5}$ D. E. Gardin, J. D. Batteas, M. A. Van Hove, and G. A. Somorjai, Surf. Sci. 296, 25 (1993).

${ }^{6}$ F. Besenbacher and J. K. Nørskov, Prog. Surf. Sci. 44, 5 (1993).

${ }^{7}$ L. Ruan, Ph.D. dissertation, Århus University, Århus, Denmark, 1994.

${ }^{8}$ F. Jensen. F. Besenbacher, E. Laegsgaard, and I. Stensgaard, Phys. Rev. B 41, 10233 (1990).

${ }^{9}$ Y. Kuk, F. M. Chua, P. J. Silverman, and J. A. Meyer, Phys. Rev. B 41, 12393 (1990).

${ }^{10}$ R. Feidenhans'l, F. Grey, M. Nielsen, F. Besenbacher, F. Jensen, E. Laegsgaard, I. Stensgaard, K. W. Jacobsen, J. K. Nørskov, and R. L. Johnson, Phys. Rev. Lett. 65, 2027 (1990).

${ }^{11}$ D. J. Coulman, J. Wintterlin, R. J. Behm, and G. Ertl, Phys. Rev. Lett. 64, 1761 (1990).

${ }^{12}$ D. J. Coulman, J. Wintterlin, J. V. Barth, G. Ertl, and R. J. Behm, Surf. Sci. 240, 151 (1990).

${ }^{13}$ J. Wintterlin, R. Schuster, D. J. Coulman, G. Ertl, and R. J. Behm, J. Vac. Sci. Technol. B 9, 902 (1991).

${ }^{14}$ F. Jensen, F. Besenbacher, E. Laegsgaard, and I. Stensgaard, Phys. Rev. B 42, 9206 (1990).

${ }^{15}$ F. Besenbacher, F. Jensen, E. Laegsgaard, K. Mortensen, and I. Stensgaard, J. Vac. Sci. Technol. B 9, 874 (1991).

${ }^{16} \mathrm{Ch}$. Wöll, R. J. Wilson, S. Chiang, H. C. Zeng, and K. A. R. Mitchell, Phys. Rev. B 42, 11926 (1990).

${ }^{17}$ F. Jensen, F. Besenbacher, and I. Stensgaard, Surf. Sci. 269/270, 400 (1992).

${ }^{18}$ F. Besenbacher, I. Stensgaard, L. Ruan, J. K. Nørskov, and K. W. Jacobsen, Surf. Sci. 272, 334 (1992).

${ }^{19}$ L. Ruan, I. Stensgaard, E. Laegsgaard, and F. Besenbacher, Surf. Sci. 296, 275 (1993).

${ }^{20}$ L. Ruan, I. Stensgaard, F. Besenbacher, and E. Laegsgaard, Ultramicroscopy 42-44, 498 (1992).

${ }^{21}$ I. Stensgaard, L. Ruan, F. Besenbacher, F. Jensen, and E. Laegsgaard, Surf. Sci 269/270, 81 (1992).
${ }^{22}$ F. P. Woodruff, Phys. Rev. Lett 72, 2499 (1994).

${ }^{23}$ R. McGrath, A. A. MacDowell, T. Hashizume, F. Sette, and P. H. Citrin, Phys. Rev. Lett. 64, 575 (1990).

${ }^{24}$ R. W. Joyner, C. S. McKee, and M. W. Roberts, Surf. Sci. 27, 279 (1971).

${ }^{25}$ H. C. Zeng, R. N. S. Sodhi, and K. A. R. Mitchell, Surf. Sci. 177, 329 (1986).

26J. L. Domange and J. Oudar, Surf. Sci. 11, 124 (1968).

${ }^{27}$ J. C. Boulliard and M. P. Sotto, Surf. Sci. 195, 255 (1988).

${ }^{28}$ H. C. Zeng and K. A. R. Mitchell, Can. J. Phys. 65, 500 (1987).

${ }^{29}$ H. C. Zeng, R. A. McFarlane, and K. A. R. Mitchell, Phys. Rev. B 39, 8000 (1989).

${ }^{30}$ V. Maurice, J. J. Legendre, and M. Huber, Surf. Sci. 129, 312 (1983).

${ }^{31}$ D. T. Ling, J. N. Miller, D. L. Weissman, P. Pianetta, P. M. Stefan, I. Lindau, and W. E. Spicer, Surf. Sci. 124, 175 (1983).

${ }^{32}$ E. Vlieg, I. K. Robinson, and R. McGrath, Phys. Rev. B 41, 7896 (1990).

${ }^{33}$ Q. T. Jiang, P. Fenter, and T. Gustafsson, Phys. Rev. B 42, 9291 (1990).

${ }^{34}$ M. Persson, S. Andersson, and P.-A. Karlsson, Chem. Phys. Lett. 111, 597 (1984).

${ }^{35}$ K. T. Leung, X. S. Zhang, and D. A. Shirley, J. Phys. Chem. 93, 6164 (1989).

36J. J. Barton, C. C. Bahr, Z. Hussain, S. W. Robey, J. G. Tobin, L. E. Klebanoff, and D. A. Shirley, Phys. Rev. Lett. 51, 272 (1983).

${ }^{37}$ C. C. Bahr, J. J. Barton, Z. Hussain, S. W. Robey, J. G. Tobin, and D. A. Shirley, Phys. Rev. B 35, 3773 (1987).

${ }^{38}$ D. A. Shirley, L. J. Terminello, and C. C. Bahr, Phys. Rev. B 39, 8003 (1989).

${ }^{39}$ A. E. Schach von Wittenau, Z. Hussain, L. Q. Wang, Z. Q. Huang, J. G. Ji, and D. A. Shirley, Phys. Rev. B 45, 13614 (1992).

40J. R. Patel, D. W. Berreman, F. Sette, P. H. Citrin, J. E. Rowe, P. L. Cowan, T. Jach, and B. Karlin, Phys. Rev. B 40, 1330 (1989)

${ }^{41}$ F. Sette, T. Hashizume, F. Comin, A. A. MacDowell, and P. H. Citrin, Phys. Rev. Lett. 61, 1384 (1988).

${ }^{42}$ Y. Ma, P. Rudolf, E. E. Chaban, C. T. Chen, G. Meigs, and F. Sette, Phys. Rev. B 41, 5424 (1990).

${ }^{43}$ S. Rousset, S. Gauthier, O. Siboulet, W. Sacks, M. Belin, and J. Klein, Phys. Rev. Lett. 63, 1265 (1989).

${ }^{44}$ M. Huber and J. Oudar, Surf. Sci. 47, 605 (1975). 
${ }^{45}$ M. L. Colaianni and I. Chorkendorff (unpublished).

${ }^{46}$ J. P. Song, N. H. Pryds, K. Glejbøl, K. A. Mørch, A. R. Thölén, and L. N. Christensen, Rev. Sci. Instrum. 64, 900 (1993).

${ }^{47}$ H. Lemke, T. Goddenhenrich, H. P. Bochem, U. Hartmann, and C. Heiden, Rev. Sci. Instrum. 61, 2538 (1990).

${ }^{48}$ I. Chorkendorff and P. B. Rasmussen, Surf. Sci. 248, 35 (1991).

${ }^{49}$ P. B. Rasmussen, P. M. Holmblad, H. Christoffersen, P. A. Taylor, and I. Chorkendorff, Surf. Sci. 287/288, 79 (1993).

${ }^{50}$ I. Stensgaard, F. Besenbacher, F. Jensen, E. Laegsgaard, and L. Ruan, Phys. Scr. T39, 314 (1991).

${ }^{51}$ M. L. Colaianni, P. Syhler, and I. Chorkendorff (unpublished).

${ }^{52}$ N. D. Lang, Phys. Rev. Lett. 56, 1164 (1986).

${ }^{53}$ N. D. Lang, Phys. Rev. Lett. 58, 45 (1987).

${ }^{54}$ D. F. Ogletree, C. Ocal, B. Marchon, G. A. Somorjai, M.
Salmeron, T. Beebe, and W. Siekhaus, J. Vac. Sci. Technol. A 8, 297 (1990).

${ }^{55}$ D. F. Ogletree, R. Q. Hwang, D. M. Zeglinski, A. Lopez Vazquez-de-Parga, G. A. Somorjai, and M. Salmeron, J. Vac. Sci. Technol. B 9, 886 (1991).

${ }^{56}$ J. G. Forbes, A. J. Gellman, J. C. Dunphy, and M. Salmeron, Surf. Sci. 279, 68 (1992).

${ }^{57}$ D Bürgler, G. Tarrach, T. Schaub, R. Wiesendanger, and H.J. Güntherodt, Phys. Rev. B 47, 9963 (1993).

${ }^{58}$ B. Marchon, P. Bernhardt, M. E. Bussell, G. A. Somorjai, M. Salmeron, and W. Siekhaus, Phys. Rev. Lett. 60, 1166 (1988).

${ }^{59}$ I. G. Dance, Aust. J. Chem. 31, 2195 (1978).

${ }^{60}$ H. Fjellvåg, F. Grønvold, S. Stølen, A. F. Andresen, R. Müller-Käfer, and A. Simon, Z. Kristallogr. 184, 111 (1988).

${ }^{61}$ D. Sanders, U. Linke, and H. Ibach, Surf. Sci. 272, 318 (1992). 
(a)

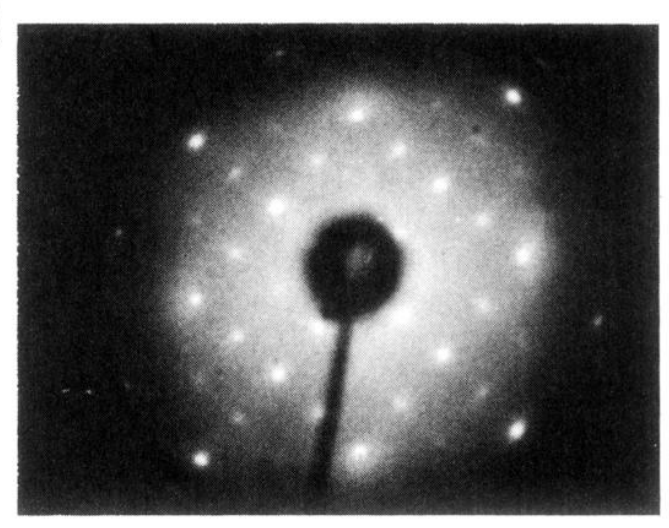

(b)

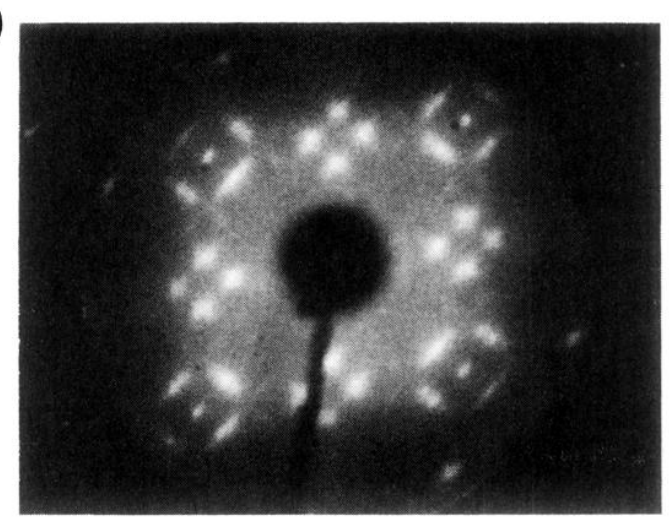

(c)

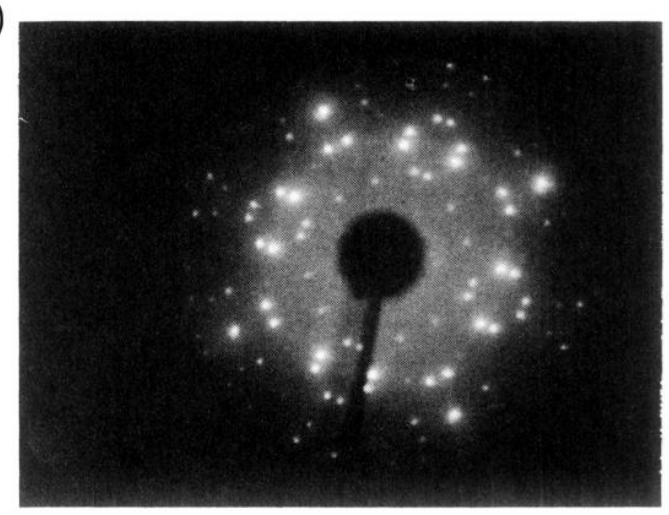

FIG. 2. LEED photos of the various sulfur structures formed on $\mathrm{Cu}(100)$ : (a) $p(2 \times 2)$ formed by $10 \mathrm{~L}$ of $\mathrm{H}_{2} \mathrm{~S}$ followed by an anneal to $573 \mathrm{~K}, E_{p}=210.9 \mathrm{eV}$; (b) a complex pattern formed by $45 \mathrm{~L}$ of $\mathrm{H}_{2} \mathrm{~S}$ with a heated filament doser followed by an anneal to $573 \mathrm{~K}, \Theta_{S} \sim 0.5 \mathrm{ML}, E_{p}=78.9 \mathrm{eV}$; (c) the $(\sqrt{17} \times \sqrt{17}) R 14^{\circ}$ pattern formed by bulk segregation of sulfur upon annealing to $1173 \mathrm{~K}, E_{p}=67.7 \mathrm{eV}$. 
(a)

(1
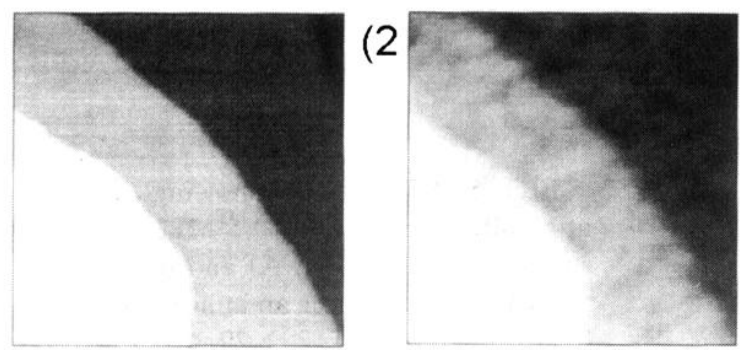

(b)

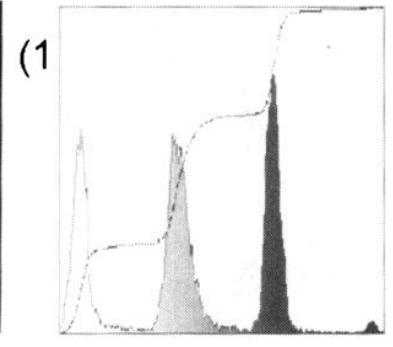

(3

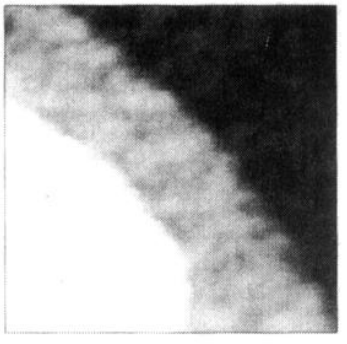

$(4$

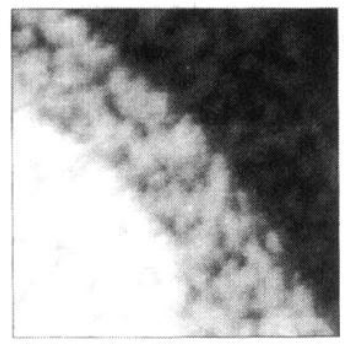

$(2$

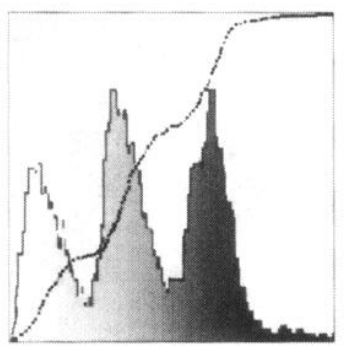

FIG. 3. (a) STM images of a $885 \times 885 \AA^{2}$ area on the $\mathrm{Cu}(100)$ surface showing the effects of $\mathrm{H}_{2} \mathrm{~S}$ exposure on the $\mathrm{Cu}(100)$ surface at room temperature: (1) clean flat terraces; (2) $6 \times 10^{3} \mathrm{~L}$ $\mathrm{H}_{2} \mathrm{~S}$; (3) $1.5 \times 10^{4} \quad \mathrm{~L} \quad \mathrm{H}_{2} \mathrm{~S}$; (4) $2.1 \times 10^{4} \mathrm{~L}$. Scans were recorded during $\mathrm{H}_{2} \mathrm{~S}$ exposure. Note that the position of the step edges remains unaffected as the terraces roughen. All images recorded at a sample bias of $+0.084 \mathrm{~V}$ and at a tunneling current of $1.17 \mathrm{nA}$. (b) Height distributions of (1) the clean $\mathrm{Cu}(100)$ surface measured from (a1), which has a total $z$ height of $6.4 \AA$; and (2) the roughened layer shown in (a4), which has a total $z$ height of $9.4 \AA$. 

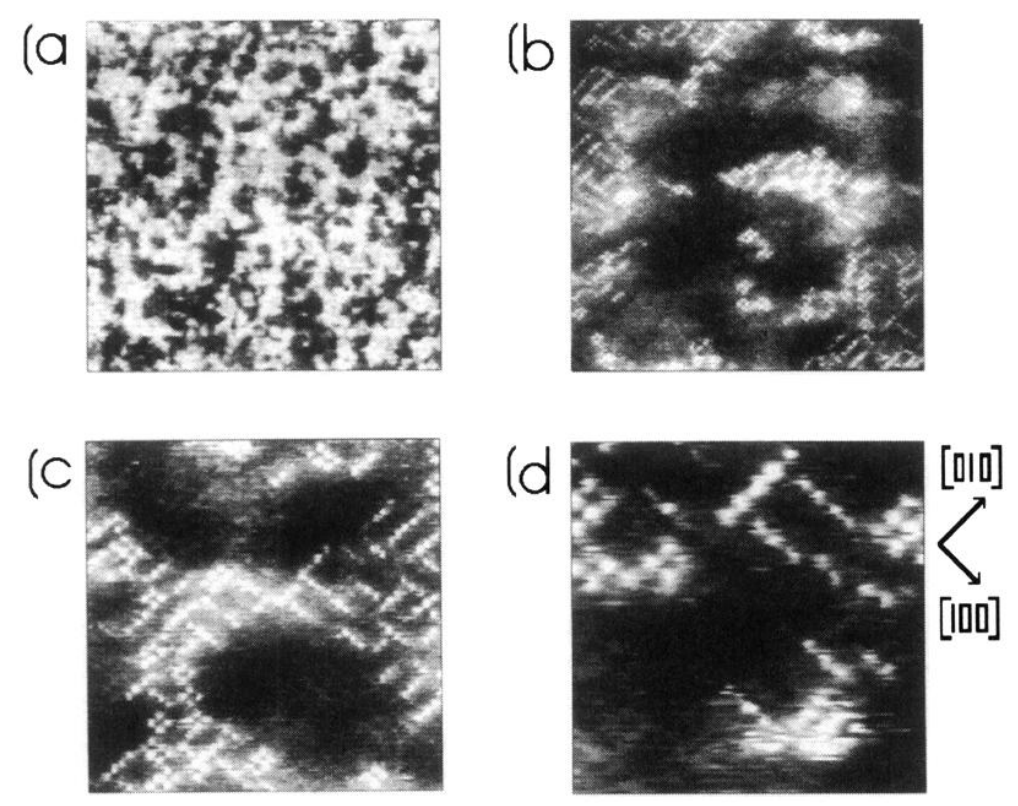

FIG. 4. STM images of the $\mathrm{Cu}(100)$ surface after being exposed to $2 \times 10^{4} \mathrm{~L} \mathrm{H}_{2} \mathrm{~S}$ at room temperature: (a) $771 \times 771 \AA^{2}$; (b) $278 \times 278$ $\AA^{2}$; (c) $139 \times 139 \AA^{2}$; (d) $69 \times 69 \AA$. The sulfur atoms are observed as protrusions in the [001] and [010] directions. Sample bias $\left(V_{b}\right)$ and tunneling currents $\left(I_{t}\right)$ were (a) $V_{b}=+0.540 \mathrm{~V}$ and $I_{t}=0.69 \mathrm{nA}$; (b), (c), and (d) $V_{b}=+0.010$ $\mathrm{V}$ and $I_{t}=1.38 \mathrm{nA}$. 

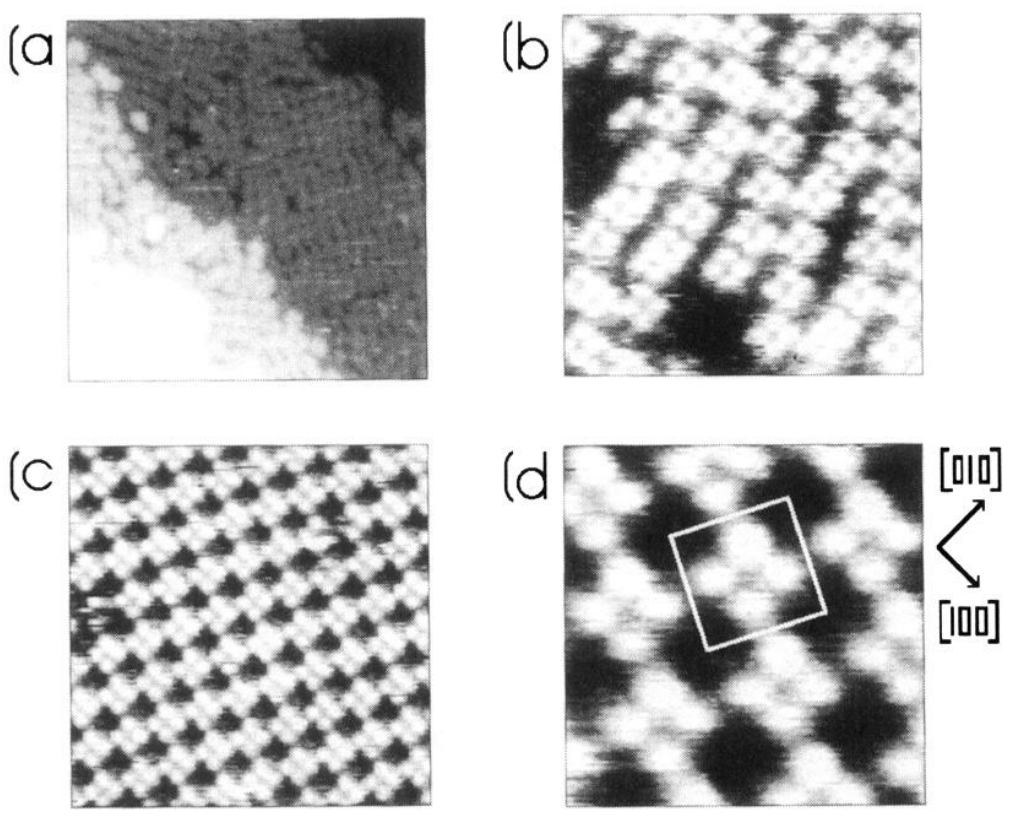

FIG. 5. STM images showing the ordering of a sulfur overlayer, $\sim 0.5 \mathrm{ML}$, on a $\mathrm{Cu}(100)$ surface. (a) $(272 \times 272 \AA)$ and (b) $(87 \times 87 \AA)$ show the surface after an anneal to $673 \mathrm{~K}$. (c) $(93 \times 93 \AA)$ and (d) $(29 \times 29 \AA)$ show the surface after an anneal to $1173 \mathrm{~K}$. Sample bias $\left(V_{b}\right)$ and tunneling currents $\left(I_{t}\right)$ were (a) $V_{b}=+0.014 \quad \mathrm{~V}$ and $I_{t}=0.29 \quad \mathrm{nA} ; \quad$ (b) $V_{b}=+0.018 \mathrm{~V}$ and $I_{t}=0.34 \mathrm{nA}$; (c) and (d) $V_{b}=+0.005 \mathrm{~V}$ and $I_{t}=2.35 \mathrm{nA}$. 


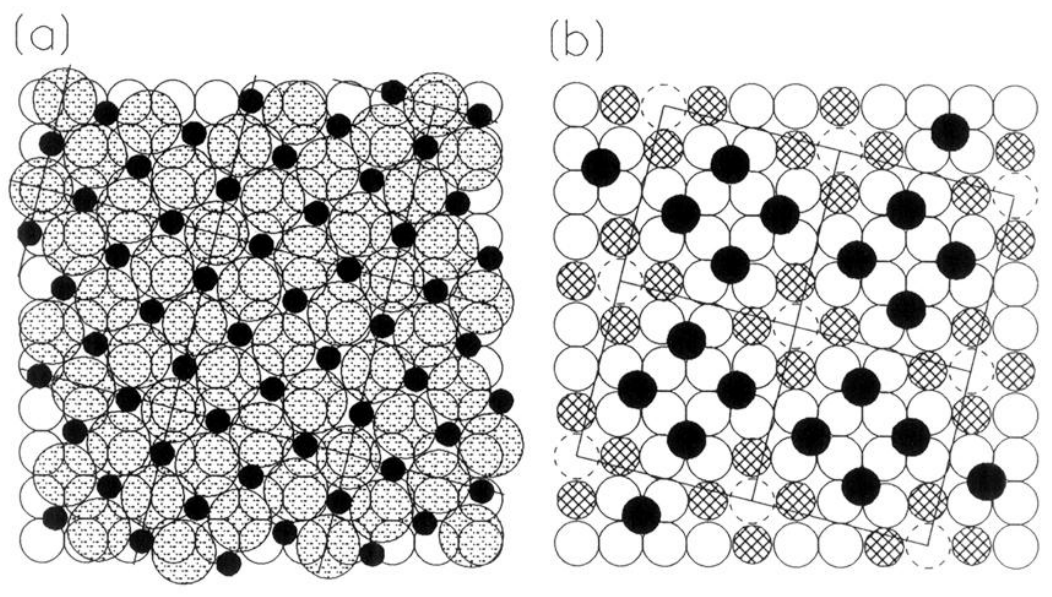

FIG. 6. (a) Model of $(\sqrt{17} \times \sqrt{17}) R 14^{\circ}$ proposed by Domange and Oudar (Ref. 26) showing a S-Cu mixed overlayer on a Cu(100) substrate. Small black circles are copper atoms and larger shaded circles represent sulfur. (b) Our proposed model based on STM analysis of the unit cell. Two types of sulfur atoms are proposed. Black circles are surface-sulfur atoms which are situated on top of pseudo-FFHS on the copper surface, and cross-hatched circles are in-plane sulfur atoms which have taken the place of terrace copper atoms within the top copper layer. The dashed circle represents a copper atom which may be absent. Spacing between the surfacesulfur atoms is measured to be $4.0 \pm 0.15 \AA$. See text for details of this model. 